\title{
El impacto de la acción parlamentaria en una política gubernamental: el caso de la política turística española
}

\author{
Juan Luis Paniagua Soto* \\ María Velasco Gozález***
}

Palabras clave: Parlamento, politicas públicas, política turística española.

\section{El Parlamento y las políticas públicas}

La variedad de análisis sobre el Parlamento, tanto desde un enfoque de cultura política como desde un enfoque institucionalista, pueden ordenarse atendiendo al criterio de cuáles son los elementos del sistema político que son observados por el investigador para analizar el Parlamento. Un primer grupo de trabajos analiza el Parlamento desde la perspectiva del diseño constitucional del conjunto, se centran en la posición de éste en relación con los distintos elementos que componen el sistema político, lo que en ocasiones se ha denominado «macroestructura de la legislatura», y adoptan un posición que podríamos denominar «macro» (Ferejohn 2001; Lanzaro 2001; Loewenberg et al. 2002; BID 2006). En un segundo grupo, en un nivel meso, encontramos reflexiones y propuestas teóricas cuyo objeto son las relaciones del Parlamento con otras instituciones concretas del sistema, generalmente con el Poder Ejecutivo aunque, cada vez con más frecuencia, con el sistema electoral y los partidos políticos, como variables influyentes en las posibilidades de funcionamiento de la institución parlamentaria (Reboredo 1998; Portero 1998; Guerrero 2000; López Nieto 2004; Saiegh 2005). Por último, encontramos investigaciones cuyo objeto son las capacidades y limitaciones de un Parlamento concreto; suelen observar, desde un nivel micro, o bien la estructura legal -los poderes formales atribuidos por la normativa y las posibilidades que los reglamentos de desarrollo y funcionamiento permiten a la institución para alcanzar sus objetivos-, o bien los factores políticos e institucionales que condicionan el funcionamiento cotidiano de la institución -las estrategias internas de los parlamentarios y los grupos ${ }^{1}$, las posibilidades de negociación según incentivos; los procesos de toma de decisiones etc.- (Patterson y Copeland 1994; Tsebelis 1999; Döring y Hallerbeg 2004).

\footnotetext{
" Catedrático de Ciencia Política y de la Administración de la Universidad Complutense de Madrid.

"Doctora en Ciencias Politicas y de la Administración y profesora de la Diplomatura en Turismo de la Universidad Complutense de Madrid.

${ }^{1}$ Desde la Economía Política se han desarrollado una línea de análisis interesante que parte de la teoría de la firma y de los contratos óptimos y analizan la denominada «actividad industrial del Congreso». La aportación inicial, de Weingast y Marshall (1988), propone entender la actividad legislativa como un «mercado de votos». Estudiando el Congreso de EEUU y la posición de sus congresistas consideran a éstos como los re-
} 
CUADRO 1

Variedad de análisis sobre el parlamento

\begin{tabular}{|l|l|l|}
\hline \multicolumn{1}{|c|}{ MACRO } & \multicolumn{1}{|c|}{ MESO } & \multicolumn{1}{c|}{ MICRO } \\
\hline $\begin{array}{l}\text { Posición del Parlamento en el conjunto } \\
\text { del sistema. }\end{array}$ & $\begin{array}{l}\text { Relaciones con otras instituciones concretas } \\
\text { (Ejecutivo, sistema electoral, partidos políticos...). }\end{array}$ & $\begin{array}{l}\text { Capacidades y limitaciones internas } \\
\text { de la institución parlamentaria. }\end{array}$ \\
\hline
\end{tabular}

Fuente: Elaboración propia.

Es cierto que también en las variedades de análisis que hemos denominado meso y micro las características del sistema político son una referencia ineludible para poder entender la propia institución, sus capacidades y funciones.

Este trabajo, que pretende observar la relación entre el Parlamento español y los procesos de elaboración de políticas públicas, se situaría, por lo tanto, en un nivel meso, aunque es necesario realizar algunas reflexiones iniciales sobre el diseño constitucional de los sistemas políticos para poder observar posteriormente las capacidades que las instituciones pueden desarrollar para intervenir en los procesos de elaboración de las políticas públicas de manera eficaz (Weaver y Rockman 1993).

Las posibilidades de que nuestro Parlamento se configure como un actor más o menos activo en el proceso de elaboración de las políticas públicas están primeramente condicionadas por la estructura básica de nuestro sistema político, que responde a las características de los regímenes parlamentarios. Brevemente diremos, como características más sobresalientes, que el modelo se construye sobre el principio de colaboración -no de separación- entre Poder legislativo y el Ejecutivo, genera Parlamentos constitucionalmente débiles ya que lo que se pretende, y se logra, es contar con gobiernos fuertes apoyados en mayorías sólidas. A cambio de la robustez, el Parlamento queda extremadamente supeditado a la intensa capacidad de dirección del Gobierno y de su Presidente, reforzado por el papel de la mayoría, lo que conlleva que las minorías que forman la oposición se debilitan. Este tipo de «parlamentarismo racionalizado» es predominante en las democracias europeas actuales y alcanza su expresión más acabada en Alemania o España.

A esta primera imagen de la posición debilitada del Parlamento en nuestro sistema político habría que sumarle el hecho de que las políticas públicas son el instrumento básico de la acción del poder ejecutivo. Se diseñan e implantan desde las organizaciones públicas que sirven al Gobierno por lo que, en principio, no parece que el Parlamento tenga capacidad alguna para intervenir en el proceso de elaboración o seguimiento.

Pero, como la doctrina señala, las políticas públicas, además de ser instrumentos para intervenir en un territorio o en sector determinado (Mény y Thoenig 1992; Lindblom 1993; Hill 1997; Considine 2005, entre otros), pueden ser observadas como espacios donde estructuras reticulares defienden valores e ideas (Sabatier y JenkinSmith 1993; Börtzel 1998; Waarden 1998; Sabatier, 1999; Fenger y Klok 2001). Si consideramos las políticas públicas como arenas políticas, más que como procesos racionales de análisis de problemas, propuestas de resolución e implantación de acciones, es más coherente preguntarse si el Parlamento puede haber desarrollado un papel más relevante de lo que inicialmente parece, si el Parlamento puede haberse convertido en un espacio deliberati-

presentantes directos de intereses de un electorado concreto que funcionaría como el principal, desde el punto de vista de la teoría de la agencia. El modo de funcionamiento de las Comisiones Legislativas en el Congreso estadounidense convierte a estas en espacios que permiten alcanzar acuerdos estables y compromiso reales sobre políticas públicas y, por tanto, en espacios altamente eficaces en términos de rendimiento institucional. La aplicación de este esquema al caso español puede verse en Caballero (2005). 
vo en donde se reflejan las diversas posiciones ideológicas sobre los mismo asuntos a través del trabajo de los Grupos parlamentarios. Estas preguntas resultan ingenuas si se plantean en un modelo de sistema político presidencial. En ese caso, el Parlamento es una institución clave para la configuración de las políticas públicas.

La importancia de la institución en el proceso de elaboración de políticas explica porqué la mayor parte de las contribuciones teóricas sobre la relación Parlamento-políticas públicas se construyen, precisamente, observando Parlamentos de este segundo modelo. Parece evidente que sus planteamientos, sugerentes y en ocasiones clarificadores, no son de aplicación para el estudio de nuestro país, aunque pueden darnos algunas claves.

Con este objetivo destacamos dos propuestas que, reflexionando sobre cuál es la posición de los parlamentos en los procesos de elaboración de políticas, tratan de construir sendas clasificaciones que resultan de interés.

La propuesta inicial de Mezey (1989) distinguía entre Parlamentos activos, reactivos, marginales y mínimos, considerando que podían clasificarse en uno u otro tipo aquellos que tuvieran las siguientes características:

- Activos: Parlamentos fuertes en relación con el proceso de elaboración de políticas y promotores activos en la construcción de la agenda política. El caso paradigmático sería el de Estados Unidos.

- Reactivos: Parlamentos dominados por el Ejecutivo, pero con capacidades para influenciar el proceso de elaboración de políticas, caso de las democracias parlamentarias europeas.

- Marginales: Parlamentos dominados por el Ejecutivo y sin ninguna capacidad para influenciar el proceso de elaboración de políticas.

- Mínimos: Puramente simbólicos, caso de los regímenes autoritarios.

La construida por Morgenstern (2002), que sirve de base al Informe del Banco Interamericano de Desarrollo La política de las políticas públicas (2006) y cuyo objetivo era situar en un mapa a los legislativos de las repúblicas presidencialistas de América Latina, distingue entre Parlamentos con las siguientes características:

a) Legislaturas relativamente limitadas: Aprueban las iniciativas del Poder Ejecutivo tras efectuar únicamente cambios menores y no son muy activas ni efectivas en la función de supervisión del Ejecutivo.

b) Legislaturas reactivas obstruccionistas: Potencialmente más activas en la formulación de políticas, pero su función es principalmente la de vetador directo, por lo general, bloqueando o aprobando iniciativas del Ejecutivo. Este tipo de legislatura rara vez participa mucho en la definición final del carácter técnico o distributivo de las políticas propuestas por el Ejecutivo ni en la supervisión activa de su ejecución.

c) Legislaturas reactivas constructivas: Pueden desempeñar las funciones que caracterizan a las legislaturas reactivas obstruccionistas, pero además pueden determinar de manera significativa el contenido de las políticas enmendando las iniciativas del Ejecutivo. También pueden desempeñar la función de supervisión con cierta eficacia.

d) Legislaturas preactivas: además de desempeñar las funciones de las legislaturas reactivas obstruccionistas y reactivas constructivas, ocasionalmente también pueden tomar la iniciativa para determinar la agenda, y elaborar propuestas de políticas propias. Ninguna legislatura de la región ha exhibido de manera permanente estas características preactivas (BID 2006: 57). 
Ambas tipologías pierden mucha capacidad explicativa cuando se aplican a Parlamentos que corresponden al otro modelo. A pesar de ello, por si obtuviéramos claves del ejercicio, reflexionaremos sobre la posición de nuestro país y los de nuestro entorno en ambas clasificaciones.

España, como el del resto de los regímenes parlamentarios europeos, se encontraría reflejado en la categoría «Parlamentos reactivos» de la clasificación de Mezey. Son Parlamentos dominados por la mayoría parlamentaria que sustenta al Gobierno; construidos por Grupos parlamentarios en los que predomina la cohesión interna y la estabilidad de los programas a lo largo de la legislatura (con la excepción más recurrente del caso italiano). Son Parlamentos que asumen, a través de sus respectivas mayorías, apoyar al Gobierno que logró la investidura tras las elecciones y cuya confianza se mantiene, salvo crisis de esa mayoría o del/los partidos que la forma. Es decir, que son excepciones que garantizan mediante una mayoría parlamentaria estable, y en la mayoría de los casos sólida, el Gobierno tenga recursos parlamentarios suficientes como para desarrollar su programa y las políticas a través de las cuales aquél se despliega.

En este marco, el papel y el lugar de las minorías parlamentarias que constituyen la oposición se circunscribe a la obtención de información, a la fiscalización, al ejercicio del control y, en función de la composición de la Cámara y de la receptividad de la mayoría, al ejercicio de iniciativas con pretensión de orientar, o reorientar, la acción del Gobierno hacia acciones y políticas que le resulten negociables.

Si volvemos a la segunda clasificación descrita, nuestro país con un parlamentarismo altamente racionalizado que cuenta con partidos políticos fuertes, potenciados por el papel que les otorga la constitución y reforzados por los efectos del sistema electoral y el sistema de listas cerradas y bloqueadas, quedaría encuadrado en la categoría de Parlamentos relativamente limitados.

Aunque en este mismo grupo deberíamos incluir a un sistema, como el italiano ${ }^{2}$, con el que existen sustanciales diferencias constitucionales partidistas y de dinámica política, lo que vuelve a señalar lo limitado de su utilidad teórica, Aún así nos permite construir un mapa de posiciones ideales que puede facilitar un primer estudio del papel de un Parlamento concreto en relación con el proceso de elaboración de políticas públicas.

\section{El Parlamento y la política turística}

El turismo es, y ha sido, una de las actividades claves de la economía española ${ }^{3}$. Ha contado, desde sus inicios, con una política diseñada para dicho ámbito que fue modificándose hasta convertirse en un conjunto singular de acciones ajustadas a la realidad turística de un país líder en el sector. Cada una de las etapas de la evolución de la política turística ha aportado una perspectiva que, siendo sucesivamente superada, dejaba en la experiencia acumulada del sector público una referencia útil para los nuevos retos. Décadas de política turística han conformado un campo de acción pública singular y profesionalizado que, sin embargo, ha generado muy poco interés a los investigadores de políticas públicas. Encontramos trabajos interesantes en el campo de la Economía Política ${ }^{4}$, y en el ámbito de la Geografía ${ }^{5}$-análisis de los impactos que en el territorio produce el turismo, las co-

\footnotetext{
${ }^{2}$ Para estudiar el papel del Parlamento en relación con el Ejecutivo y la participación de otros actores en relación con las políticas públicas en el caso italiano véase Caretti y Morisi (2001).

${ }^{3}$ En 2005 el turismo supuso el 11 por 100 del PIB de la economía española (INE 2006). Se recibieron 55,6 millones de turistas internacionales recibidos. Por lo que respecta al turismo nacional, se realizaron 111,8 millones de viajes, el 93,9\% estos viajes se realizaron dentro del territorio nacional. El 6,1\% restante fueron viajes con destino en el extranjero. El empleo generado por la actividad turística, según la Encuesta de Población Activa, en el año 2005, creció un 4,8\% en relación con 2004, hasta situarse en 2.345 .415 ocupados (ITE 2005).

${ }^{4}$ Cals (1987), Figuerola (1993 y 2000), Aguiló y Vich i Martorell (1996), Bote (1996a y b), Pellejero (1999), García Reche y Nácher (1999) y Monfrot (2000).

${ }^{5}$ Vera y Marchena (1990), Antón y López Palomeque (1996), Troitiño (1996), Vera et al. (1999), Blanquer (2002) y Vars (2004).
} 
rrientes o flujos turísticos, la ordenación del territorio, o la planificación de los recursos existentes-, pero prácticamente ninguno abordado por politólogos en el campo de Análisis de Políticas ${ }^{6}$ (Velasco 2004). En general, hay poco desarrollo teórico para un ámbito de tal importancia.

Si pasamos a observar la realidad parlamentaria, ya en la Legislatura Constituyente encontramos iniciativas relacionadas con el sector en nuestro Parlamento y, desde entonces, el fenómeno es uno de los asuntos que reciben atención de forma habitual. En un estudio anterior analizamos cuántas iniciativas de los Grupos parlamentarios del Congreso se habían centrado en el turismo, observando si los Grupos habían utilizado iniciativas relacionadas con la función de dirección para incorporar nuevas ideas a la política turística diseñada por el Gobierno ${ }^{7}$. Tratamos de poner en conexión la capacidad de respuesta política de los Gobiernos en la práctica parlamentaria ${ }^{8}$, con el rendimiento del Congreso de los diputados en relación con la política turística. Una de las conclusiones era que la política turística había sido objeto de una actividad parlamentaria homogénea (incluso comparando periodos de gobiernos en minoría y en mayoría, y periodos con alternancia política) y fuertemente vinculada a dos actitudes reactivas: la idea de un control posterior de las acciones lideradas por el Gobierno o el trabajo sobre cuestiones que se incorporaban a la agenda política de manera repentina (Subirats 1994).

Pero el análisis, similar a otros trabajos sobre rendimiento parlamentario, no nos permitía profundizar en una cuestión crítica: si la institución interviene en la configuración del objeto de la política pública concreta, ¿`se incorporan gracias al trabajo parlamentario dimensiones nuevas en las definiciones de los problemas que se abordan desde el sector público?, ¿se enriquecen los planes y programas a través del debate de los grupos?, ¿plantean los Grupos soluciones o líneas de acción que son tenidas en cuenta por el Gobierno?...

Por ello, nos planteábamos, a manera de conclusión, una segunda pregunta. Aunque las características de nuestro sistema político impidan al Parlamento tener un papel demasiado determinante en la configuración de la política turística es posible plantear «(...) al menos como hipótesis, que en el proceso de configuración de los límites de los problemas y en la articulación de las propuestas de resolución sobre las que trabajan los decisores públicos el Parlamento pudiera tener un papel activo, particularmente los Grupos parlamentarios que expresan su pluralismo» (Paniagua y Velasco 2006). Quizá si observamos los contenidos de las iniciativas parlamentarias comprobemos que el trabajo parlamentario posibilita incorporar nuevas perspectivas en las políticas o, dicho de otro modo, quizá el Parlamento se incorpora, a través del debate y trabajo en la Cámara, al diseño de las políticas públicas?.

Pero, ¿es inicialmente plausible entender que en el ámbito de la política turística pueda existir un debate diferenciado defendido por distintos Grupos parlamentarios? Como en todos los ámbitos para los que se diseña e implanta un curso de acción colectiva, la elección de cuáles son los aspectos relacionados con el turismo que serán objeto de la acción pública no es técnica, es una elección puramente política: el turismo implica un flujo económico de gran interés para el Estado; el turismo implica una multiplicación de los residentes en zonas específicas del territorio con la consiguiente presión sobre los servicios públicos que se prestan

\footnotetext{
${ }^{6}$ En España, Velasco (2004 y 2005 a y b). Ver también Pearce (1996), Keller (1999) y Hall (2000).

${ }^{7}$ El estudio, más amplio de lo descrito, se basó en un análisis cuantitativo de la actividad realizada por el Congreso de los Diputados en relación con la política turística desde la Legislatura Constituyente hasta el final de la VII Legislatura. Se observaron, por legislaturas, los tipos de iniciativas parlamentarias según función legislativa, de control y de orientación política (Paniagua y Velasco 2006).

${ }^{8}$ La variable capacidad de respuesta política de los Gobiernos en la práctica parlamentaria suele observarse a través diferentes indicadores: tipo de Gobierno; duración media de los Gobiernos, cohesión del Gobierno y de la oposición, o vínculo del Poder Legislativo con el Poder Ejecutivo (Putnam et al. 1985; Delgado 2005).

${ }^{9}$ Esta reflexión entronca con los análisis de la «no decisión», de las tres dimensiones del poder de Lukes (1974) y de cualquier otra propuesta teórica que trate de demostrar como la construcción política de los problemas sociales es una dimensión básica del poder en la actualidad, como Fisher y Forester (1993).
} 
en las mismas; el turismo implica un intercambio cultural que puede ser beneficioso o perjudicial; el turismo conlleva una enorme presión urbanística en determinadas zonas; la concentración de población y nuevos productos turísticos, como el golf, suponen un uso intensivo de recursos escasos, como el agua, por ejemplo. Parece razonable suponer que diferentes Grupos parlamentarios priorizarán de forma diversa la importancia de todos estos aspectos.

El turismo, por un lado, representó desde sus inicios una «oportunidad económica» para los decisores, la formulación de la política turística resulta un supuesto interesante para observar como los decisores convierten una coyuntura favorable en una oportunidad política. El peso económico y laboral de la actividad es de tal magnitud que los Gobiernos son, junto al empresariado turístico, beneficiarios netos de los resultados positivos de la actividad turística. El turismo contribuye como actividad económica a garantizar un nivel de bienestar económico en el país; además, el turismo es una industria exportadora, por lo que ingresa de divisas; también es destacable la diseminación de las unidades de negocio finales, las altas economías que genera... todo ello podría explicar el alineamiento que, en este caso, podría producirse entre los grupos empresariales y el Gobierno.

Pero, por otro lado, el propio crecimiento de la actividad ha hecho que su valor como actividad económica colisione con otros valores en paulatino ascenso social: la defensa de un uso racional de los recursos naturales, base del desarrollo de los productos turísticos; la protección de poblaciones expuestas a fuertes procesos de aculturación, en donde el turismo es uno de los agentes más devastadores; o la necesaria reinversión de parte de los beneficios que genera la actividad en la conservación de los bienes de patrimonio cultural que son reclamos turísticos, colocan a la política turística en un espacio intermedio entre las políticas económicas o industriales y las nuevas políticas simbólicas relacionadas con estos valores.

El objetivo de este trabajo es observar si los cambios en la política turística tienen alguna relación con el trabajo impulsado por los Grupos parlamentarios a través de iniciativas en el Congreso de los Diputados.

El diseño metodológico de la investigación que lo sustenta puede resumirse de la siguiente forma. Los cambios en la política turística -en este caso variable independiente- se observarán a través las modificaciones en los instrumentos de política turística del periodo que se describirán en el próximo epígrafe (la fuente de estos datos es también de una investigación anterior: Velasco 2004). Para analizar el contenido de las iniciativas parlamentarias relacionadas con la política turística se las agrupó en categorías, previamente, mediante una tabla de codificación. Con ella se clasificaron todas las iniciativas pertinentes del periodo conforme a dos criterios: un criterio sustantivo, que recogí el tema a que hacía referencia, y un criterio territorial, señalando si la iniciativa tuvo carácter local, regional, autonómico o nacional. La construcción de la codificación sustantiva se basaba a su vez en el análisis previo del los atributos básicos del turismo y sus componentes, así como de la política turística, en su vertiente teórica.

Con el conjunto de las iniciativas puede observarse, a través de cuáles han sido los objetos de trabajo, qué asuntos relacionados con la política turística han sido de interés para los Grupos parlamentarios; si han cambiado con el paso del tiempo los temas de las iniciativas parlamentarias en la materia; si los contenidos de las iniciativas responden a un patrón que identifique asuntos concretos vinculados a posiciones ideológicas o de partido; si los Grupos cambian el contenido de sus intervenciones cuando son Gobierno u oposición; si hacen uso de las posibilidades reglamentarias que existen para orientar el curso de una política o, si habiendo hecho uso de éstas, modifican, a su vez, la acción de los decisores públicos en la materia. Los resultados de dicha investigación se exponen a continuación en el presente trabajo. 


\section{Temas presentes en el trabajo parlamentario sobre política turística}

Las cuestiones más recurrentes sobre las que se han promovido iniciativas parlamentarias pueden agruparse en nueve grandes categorías. Para seleccionarlas hemos tenido en cuenta dos criterios previos: los instrumentos básicos de la política turística y los temas que, por su presencia, son protagonistas de la misma.

Consideremos que los instrumentos de los que dispone un Gobierno para intervenir en un asunto específico, en un espacio determinado o en relación con unos destinatarios concretos pertenecen a alguna de las siguientes categorías:

a) Instrumentos organizativos (creación, modificación de estructuras de naturaleza diversa para la acción pública en una materia concreta).

b) Programáticos ${ }^{10}$ (planes -conjunto ordenado de acciones y programas que contienen el proyecto político que tiene un gobierno para un asunto determinado ${ }^{11}$ y programas- serie de actuaciones relacionadas entre sí y diseñadas por el Gobierno con el fin de generar un efecto en una faceta concreta de un asunto público).

c) Normativos (normas de carácter vinculante y de aplicación directa).

d) Financieros (estímulos económicos articulados a través de cualquiera de las fórmulas previstas en la ley: créditos, ayudas económicas reembolsables, subvenciones...).

e) Y de comunicación (campañas de sensibilización, promoción, foros...).

Esta clasificación nos da un primer esquema de la posible clasificación del contenido de las iniciativas en relación con el turismo. Hemos suprimido algunas -porque no existen- y hemos añadido algunas cuestiones que han aparecido como grupos de ideas importantes en el debate político.

En la siguiente tabla podemos observar el número de iniciativas que se impulsan por los diferentes Grupos parlamentarios en relación con los principales asuntos que configuran la política turística en el periodo: conjunto.

También incorporamos una imagen gráfica expresiva de cuál es el peso de cada una de ellas respecto del

Veamos cada uno de los temas, desagregándolos en varias categorías que permiten ir refinando el análisis.

\footnotetext{
${ }^{10}$ Los instrumentos son categorías ideales que nos permiten ordenar iniciativas muy desiguales y de difícil comparación que son puestas en marcha por los mismos decisores. Cada instrumento responde a una naturaleza, objetivos y carácter propios, y es su uso alternativo o simultáneo el que permite conocer las estrategias reales de la política (Velasco 2004).

${ }^{11}$ No todas las políticas públicas acaban concretándose en documento expreso. Cuando lo hacen, recogen el conjunto de acciones y estrategias que permitirán conseguir los objetivos y, por lo tanto, incorporan los distintos instrumentos que se ponen en marcha en relación con un asunto determinado (sirvan como ejemplo, el Plan Nacional sobre Drogas, el Plan Nacional de Residuos Urbanos, el Plan Nacional de Accesibilidad, el Plan Avanza, el IV Plan de Igualdad de Oportunidades entre Hombre y Mujeres...).
} 
TABLA 1

Temas objeto de las iniciativas según legislaturas

\begin{tabular}{|l|c|c|c|c|c|c|c|c|c|}
\hline & Con. & I & II & III & IV & V & VI & VII & TOTAL \\
\hline 1. Política turística & 1 & 9 & 27 & 16 & 162 & 25 & 101 & 68 & 409 \\
\hline 2. Instrumentos organizativos & 1 & 5 & 11 & 2 & 42 & 54 & 35 & 31 & 181 \\
\hline 3. Planes & & 2 & 1 & 0 & 13 & 21 & 63 & 34 & 134 \\
\hline 4. Programas & 1 & 4 & 12 & 139 & 34 & 32 & 137 & 113 & 472 \\
\hline 5. Datos estadísticos & & & 12 & 11 & 16 & 4 & 13 & 32 & 88 \\
\hline 6. Instrumentos financieros & & 7 & 15 & 25 & 44 & 50 & 100 & 43 & $\mathbf{2 8 4}$ \\
\hline 7. Ordenación del sector & 1 & 7 & 11 & 9 & 12 & 17 & 45 & 12 & 114 \\
\hline 8. Infraestructura y servicios & & 1 & 8 & 4 & 11 & 5 & 13 & 22 & $\mathbf{6 4}$ \\
\hline 9. Paradores & 1 & 2 & 18 & 25 & 21 & 48 & 121 & 89 & 325 \\
\hline
\end{tabular}

Fuente: Elaboración propia.

\section{GRÁFICO 1}

Objeto de las iniciativas relacionadas con turismo

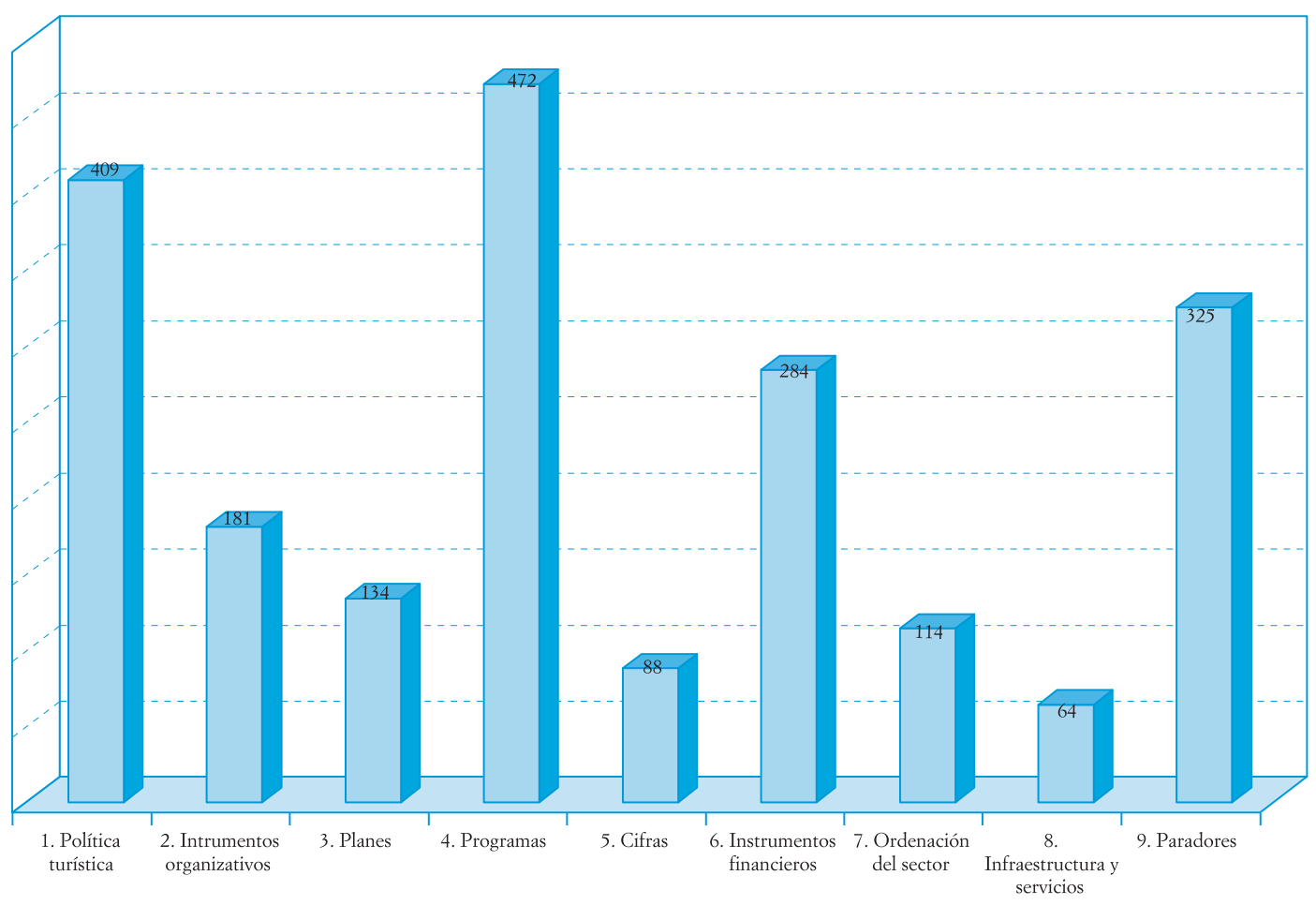

Fuente: Elaboración propia. 


\subsection{La política turística del Gobierno central}

A lo largo de las siete legislaturas estudiadas, los Grupos parlamentarios promueven 360 iniciativas cuyo objeto es la política turística que está impulsando el Gobierno central. Analizando su contenido encontramos tres ámbitos de trabajo específicos:

\section{a) Iniciativas que consideran la política turística de manera global}

En este epígrafe se encuentran los trabajos realizados por los Grupos parlamentarios y que han tenido por objeto la acción publica en materia de turismo, considerando al sector globalmente, sin descender a aspectos sectoriales o concretos del mismo. Podemos destacar por ejemplo:

- Medidas de política general que tiene previstas el Gobierno para relanzar y consolidar el futuro de la actividad turística;

- Realización de un nuevo modelo de política turística; o

- Situación del diálogo entre Comunidades Autónomas, Ayuntamientos y agentes sociales para reorientar el sector turístico.

Sólo en dos ocasiones estas iniciativas se han utilizado como instrumento de orientación política: en la III Legislatura el Grupo Coalición Popular presentó una proposición no de ley ante el Pleno para que el Gobierno remitiera al Congreso un proyecto de ley de promoción y ordenación del turismo en España; el Pleno acordó instar al gobierno a celebrar un debate sobre la situación del sector en España. Esta iniciativa tuvo un impacto relevante en la política turística ya que en siguiente periodo de sesiones se creó, también a través de una proposición no de ley en Pleno presentada por el Grupo Socialista, una Ponencia parlamentaria para el análisis del sector turístico que elaboró un informe que fue el germen del primer plan en materia de turismo en el periodo democrático, el Plan Futures.

En la VI Legislatura se aprobó, a propuesta del Grupo Federal Izquierda Unida-Iniciativa per Catalunya una moción consecuencia de interpelación urgente que pretendía que el Gobierno impulsara una política en materia turística y que adoptara medidas para mejorar la capacidad competitiva de la industria turística española. A pesar de ser aprobada, no se ha observado ningún efecto posterior en los decisores.

\section{b) Iniciativas que se interesan por la política turística diseñada e implantada para impulsar el sector en un territorio concreto}

Son las iniciativas que reflejan de manera más clara el trabajo individual de los parlamentarios por sus circunscripciones $^{12}$. Son, por ejemplo: potenciación del turismo en Ceuta, programas de impulso y promoción del turismo en la provincia de Ourense, actuaciones del Ministerio para fomentar el turismo en las Islas Canarias, etc.

${ }^{12}$ Al haber incorporado en la codificación el ámbito territorial al que la iniciativa hace referencia, es posible ver el grado de concentración de las iniciativas en espacios concretos. 
c) Iniciativas que son respuesta a un problema coyuntural que afecta al sector turístico.

Se caracterizan por ser acciones reactivas que trasladan al Parlamento dos tipos de cuestiones:

1. Problemas coyunturales del sector que se perciben como graves: Crisis del sector turístico español, estancamiento de la afluencia turística en el litoral mediterráneo, descenso turismo en España, etc. Sólo en una ocasión se utiliza una iniciativa de orientación política en este ámbito: durante la IV Legislatura se presenta una moción consecuencia de interpelación urgente relativa a la crisis del sector turístico y que es rechazada.

2. Problemas que ha irrumpido en la agenda de Gobierno y que afecta al sector turístico como: Presiones de EEUU en la aplicación de la Ley Helms Burton sobre empresas hoteleras españolas en Cuba, impacto de la Guerra del Golfo Pérsico en el turismo hacia la Costa del Sol, hundimiento del buque Prestige frente a las costas gallegas, etc.

En relación con estos temas se presentaron dos proposiciones no de ley en Comisión (para elaborar un plan de desarrollo promoción del turismo de la Costa da Morte y para aprobar un Plan de Dinamización turística de la Costa da Morte), pero ambas caducaron.

\section{GRÁFICO 2}

\section{Iniciativas cuyo objeto es la política turística del Gobierno central}

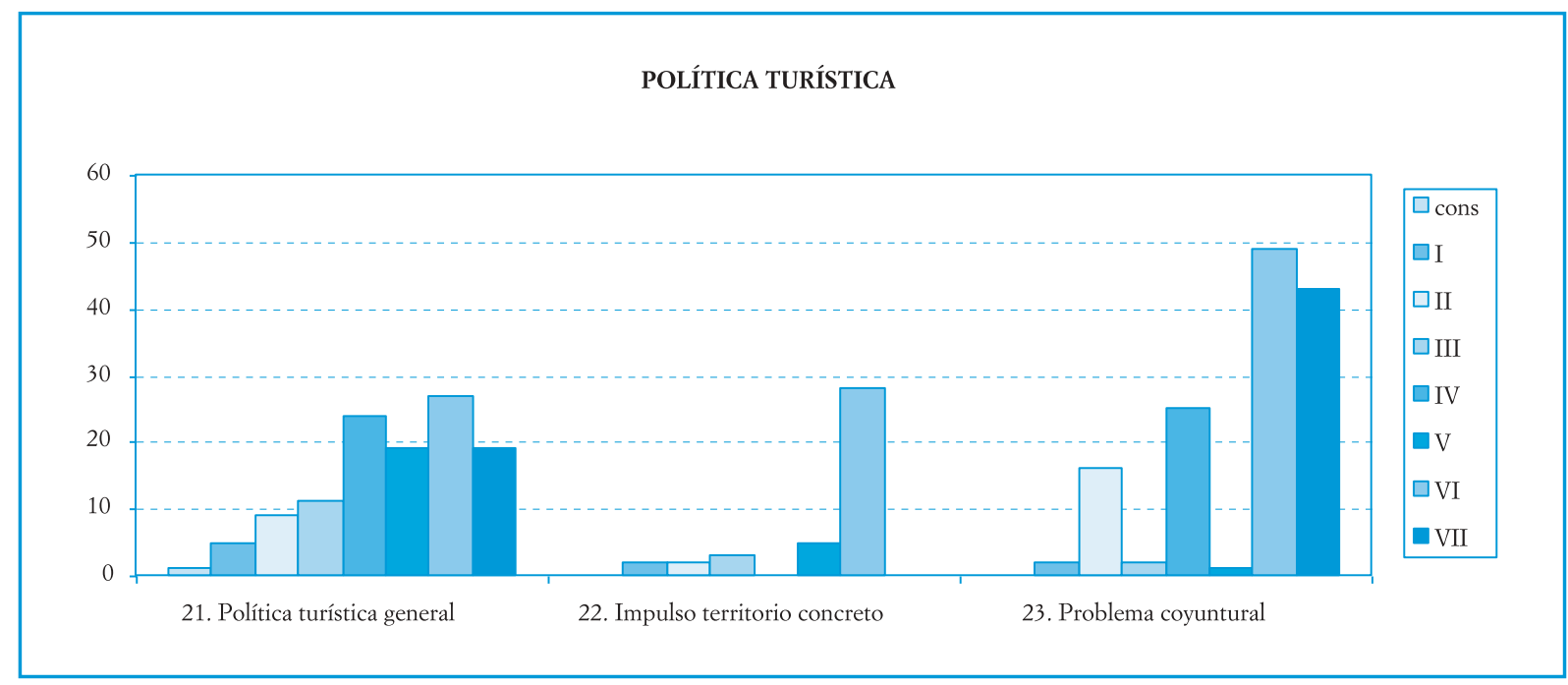

Fuente: Elaboración propia.

\subsection{Instrumentos organizativos}

En materia de política turística podemos distinguir entre estructuras administrativas tradicionales (Direcciones Generales, Subsecretarías, etc.), otras estructuras ejecutivas dependientes de las anteriores (organismos autónomos o entes públicos que persiguen objetivos concretos de política turística como la Escuela Oficial de Turismo o, de mayor importancia, Turespaña) y, por último, estructuras de cooperación de naturaleza estrictamente pública (como la Comisión Interministerial) o con participación de agentes privados, públicos e institucionales (como el Consejo Promotor de Turismo). 
Las iniciativas relacionadas con instrumentos organizativos son aquellas que se refieren a las actuaciones llevadas a cabo por los responsables públicos en una materia determinada o al funcionamiento de las diferentes organizaciones que prestan sus servicios en relación con ésta. Las Oficinas de Información Turística, en especial las que están situadas en el exterior, ocupan un número significativo de iniciativas durante la V Legislatura, periodo en donde la oposición mantiene una estrategia de desgaste al Gobierno que apoya en los casos de corrupción y mal funcionamiento de las instituciones. Es también el sentido del uso de la iniciativa parlamentaria denominada Petición de Informe: cuando se examina su contenido se comprueba que se trata destacar por parte de la oposición el alto número de trabajos que el Instituto de Estudios Turísticos encarga a consultoras externas.

Por el uso que hacen los Grupos, las iniciativas que se centran en los instrumentos organizativos se relacionan de manera clara con la función de control. Sólo en tres ocasiones (de un número total de 255) los Grupos hacen alguna propuesta de orientación política en relación con creación o modificación de los instrumentos organizativos de que dispone la política turística y ninguna de ellas prospera. Y, además, se puede comprobar que, por su contenido, todas ellas hacen referencia a asuntos de escasa relevancia.

En la V Legislatura el Grupo Popular tramita una proposición no de ley en Comisión para la comparecencia trimestral del Subsecretario del Ministerio de Comercio y Turismo para dar cuenta de la ejecución de presupuesto, propuesta que es rechazada. En la VI Legislatura el Grupo Socialista presenta una proposición no de ley en Comisión para que las administraciones turísticas cumplan los requisitos necesarios para facilitar la accesibilidad y movilidad de personas con discapacidad. El Grupo Popular, aunque es el partido que gobierna, presenta y retira, un proposición no de ley en Comisión para la creación de un observatorio del turismo, cuestión que estaba comprometida en su Plan de Actuaciones en Materia Turística de la Administración General del Estado; el Observatorio fue creado, publicado en el Boletín Oficial del Estado y nunca puesto en marcha.

\section{GRÁFICO 3}

Iniciativas cuyo objeto son los instrumentos organizativos de la política turística

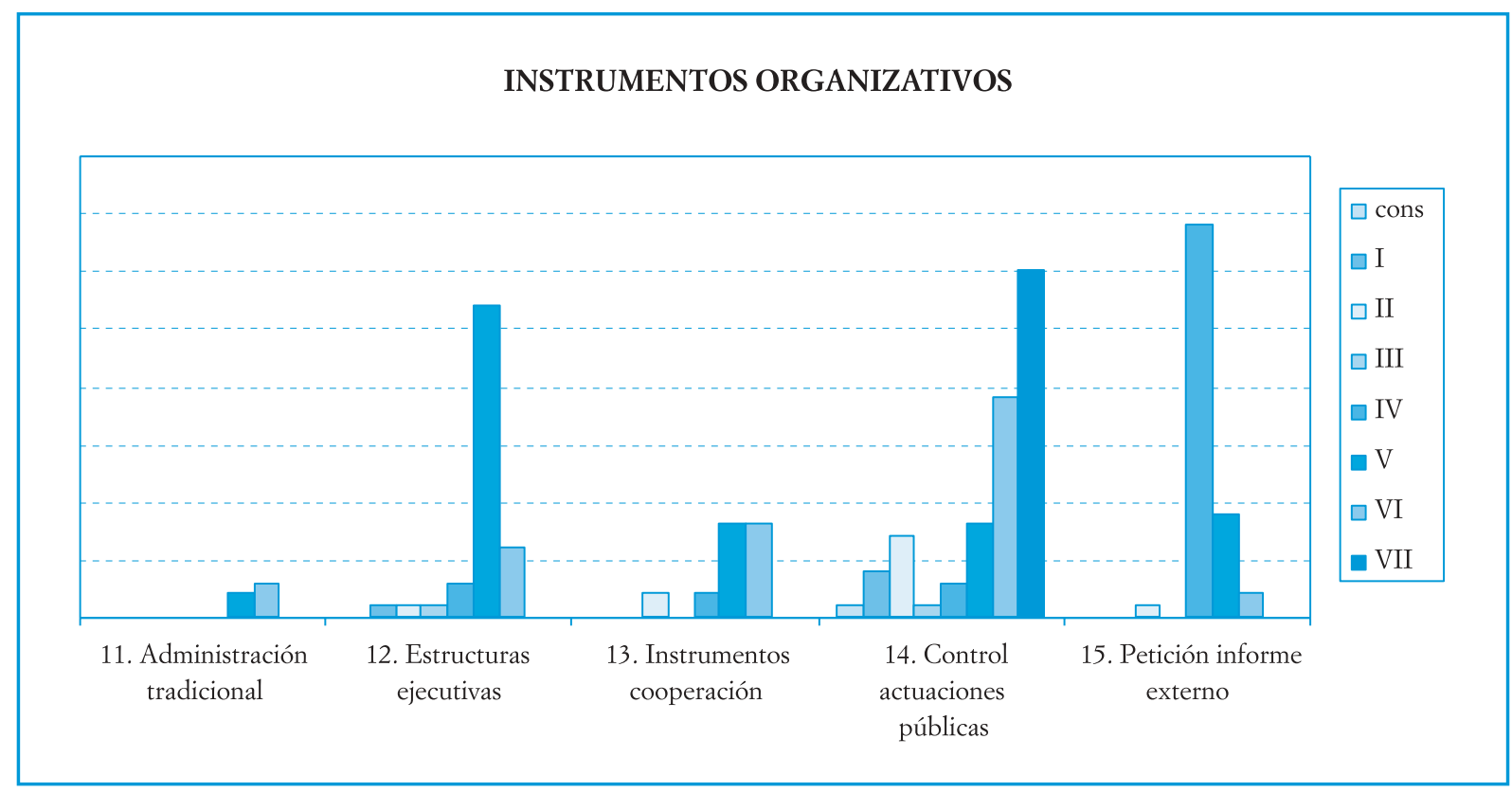

Fuente: Elaboración propia. 
Llama la atención la escasa presencia de iniciativas que tengan por objeto los instrumentos de cooperación. En materia de turismo se recupera, a partir de la V Legislatura, la Comisión Interministerial de Turismo y se institucionaliza la Conferencia Sectorial.

Sólo en cuatro ocasiones se presentan preguntas al Gobierno con respuesta escrita sobre el funcionamiento de la Conferencia Sectorial de Turismo: en la V Legislatura sobre las reuniones celebradas por la Conferencia Sectorial de Turismo a partir del mes de octubre del año 1993; en la VI Legislatura sobre una propuesta de Turespaña a la Conferencia Sectorial de Turismo para ejecutar un plan de coordinación e informatización de la información turística; sobre la participación a los entes locales en la Conferencia Sectorial de Turismo y sobre la fecha prevista para convocar la Conferencia Sectorial de Turismo.

En relación con la Comisión Interministerial de Turismo, durante la V Legislatura se presentan algunas iniciativas. Tres de ellas sobre la previsión de su constitución, una indagando el número de reuniones y de las otras, que entran en contenidos de mayor alcance, dos caducaron y no se volvieron a plantear: una sobre la puesta en marcha de la comisión conjunta de valoración, creada por la Comisión Interministerial de Turismo, para analizar los criterios a aplicar a proyectos de turismo rural (caducada); otra sobre la promoción de productos alimentarios españoles y de su gastronomía de acuerdo con las resoluciones aprobadas por la Comisión Interministerial de Turismo (caducada) y una tercera sobre los acuerdos o conclusiones a que ha llegado el grupo de trabajo denominado «fiscalidad turística». En la VI Legislatura la única pregunta es sobre si se va a potenciar la Comisión.

\subsection{Planes concretos que se impulsan en el marco de la política turística}

Dentro de este grupo de iniciativas también distinguiremos entre las que versan sobre los planes generales aprobados para el turismo; los planes que se centran en el impulso de destinos concretos y los planes que impulsan productos turísticos determinados.

\section{a) Iniciativas que se centran en planes generales}

Un plan general es el instrumento político básico que contiene el conjunto de acciones cuyo fin es intervenir en el sector turístico en su totalidad. Es el resultado de un proceso de planificación y conlleva la determinación de unos objetivos, la identificación de unos instrumentos para alcanzarlos y la dotación de los medios necesarios para su cumplimiento.

Durante las siete legislaturas, en materia de turismo se aprueban los siguientes: en la IV Legislatura se aprueba el Plan Marco de Competitividad del Turismo Español, Plan Futures 1992-1995; en la V Legislatura se aprueba el Plan Marco de Competitividad del Turismo Español, Plan Futures 1996-1999, previamente acordado en la Conferencia Sectorial del Turismo; en la VI Legislatura se aprueba el Plan de Estrategias y Actuaciones de la Administración General del Estado en Materia Turística de 1997; y en la VII Legislatura se aprueba el Plan de Calidad Turística Española (2000-2006).

Las iniciativas parlamentarias que componen este grupo son del tipo: Aprobación de un Plan Estratégico para el Sector Turístico, ejecución del Plan de Calidad Turística en 1997, evaluación Plan Futures, etc.

Se han presentado dos iniciativas relacionadas con la función de impulso, ambas en la VI Legislatura. Prosperó la presentada por el Partido Popular para la elaboración y desarrollo de un plan de impulso a la ofer- 
ta turística especializada, pero tampoco Los decisiores elaboraron una estrategia concreta derivada de dicha proposición no de ley.

\section{b) Planes centrados en destinos}

A partir del segundo Plan Futures (1996) se recurre de manera cada vez más frecuente, como forma de intervención del Gobierno central en materia de turismo, a la elaboración de planes centrados en destinos. Las características de este tipo de planes son: considerar un destino determinado desde una perspectiva global integradora; tener en cuenta dos realidades turísticas diferenciadas: la de los destinos tradicionales de sol y playa (para los que se elaboran los planes de excelencia) y la de los nuevos destinos turísticos (que son objeto de planes de dinamización); promover la coparticipación de todos los niveles administrativos a través de la cofinanciación de los programas; incorporar a representantes empresariales de los subsectores turísticos y, por último, considerar e implicar en un proyecto común al resto del tejido económico y social del destino, aunque no pertenezca de manera directa al sector (Velasco 2004).

En el Congreso de los Diputados se detecta, desde la VI Legislatura en que se extiende su uso, un interés creciente por esta herramienta. Tanto que, durante la VI y VII Legislatura el número de iniciativas que se interesan por planes concretos alcanzan casi la misma cifra que todo el trabajo realizado por la Cámara sobre planes generales a lo largo de todo el periodo que abarca nuestro estudio.

Son objeto de estas iniciativas: el contenido de los planes de excelencia turística y desarrollo de los mismos en la Comunidad Autónoma de Andalucía en los últimos cinco años: planes de dinamización turística aprobados y subvencionados por la Secretaría General de Turismo durante el año 2001, previsiones en relación con los planes de excelencia turística de las Islas Baleares para el año 2004, etc.

En la VI Legislatura se presentan tres proposiciones no de ley en Comisión relacionadas con planes centrados en destinos. La primera, en la Comisión de Defensa, por Grupo Mixto, para que se establezcan medidas para potenciar el turismo y la pesca en la municipio de Barbate (Cádiz) y alejar la presencia militar de la zona. Es aprobada con modificaciones. La segunda, presentada por el Grupo Federal Izquierda Unida-Iniciativa per Catalunya, tenía por objeto la realización de acuerdos necesarios para el desarrollo de un nuevo Plan Futures para Torremolinos (Málaga), caducó. Y la tercera, presentada por el Grupo Federal Izquierda Unida, para continuar los Planes de Excelencia Turística de Torremolinos, Benalmádena y Málaga, fue aprobada con modificaciones.

\section{c) Iniciativas en donde se observa la relación del sector turístico con problemas relacionados con la planificación territorial}

Ha sido objeto de una categoría específica aquellas iniciativas que se centraban en la difícil relación entre el turismo y la planificación territorial. Sólo en 16 ocasiones durante los veinticinco años analizados se plantean cuestiones sobre este asunto. Y de ellas, siete están relacionadas con un estudio de la Confederación Hidrográfica del Tajo relacionado con el Embalse de San Juan (Madrid), un espacio turístico completamente diferente a los destinos tradicionales. 


\section{GRÁFICO 4}

Iniciativas cuyo objeto son planes concretos

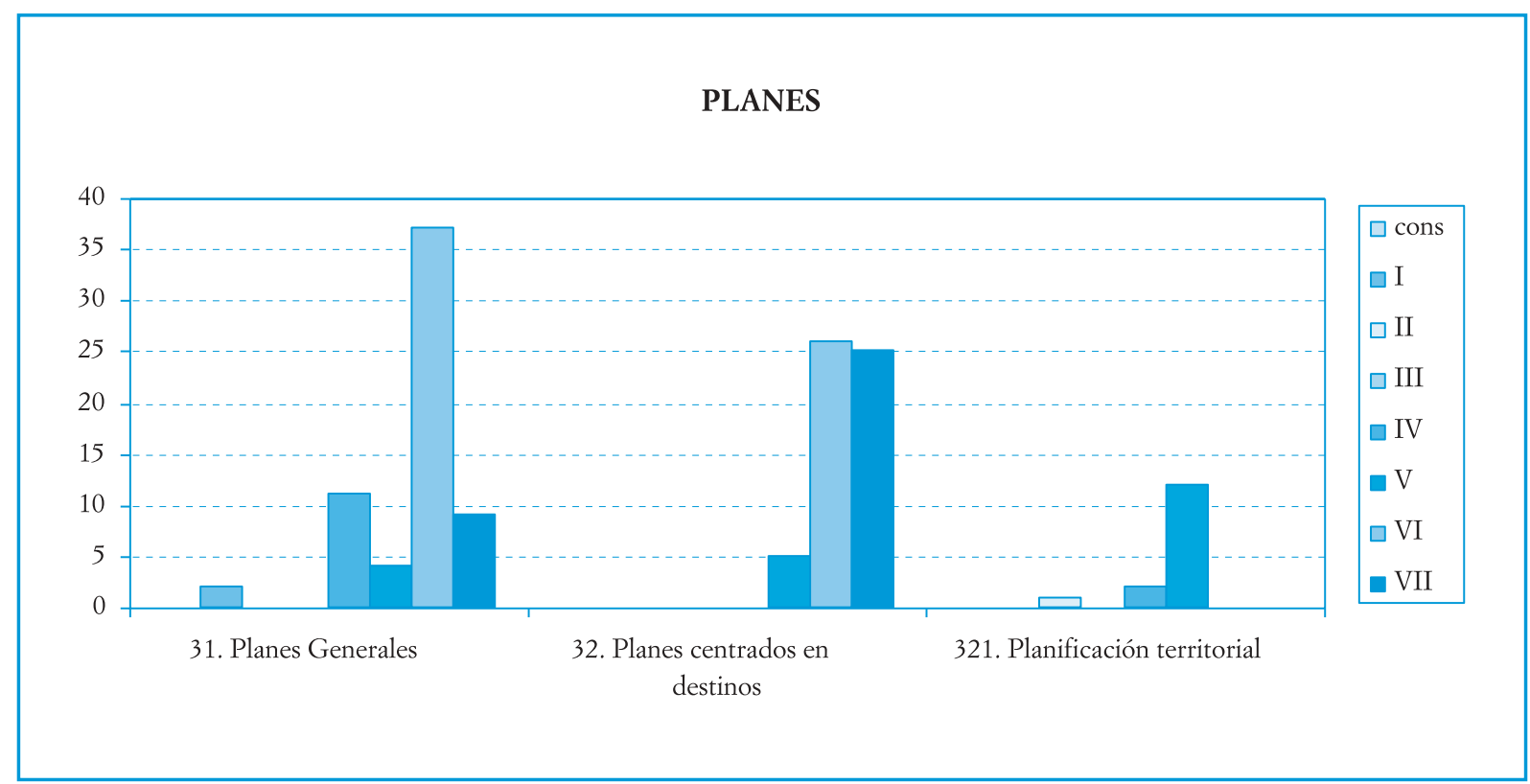

Fuente: Elaboración propia.

\subsection{Programas específicos para el turismo}

Los programas son acciones, o conjuntos de acciones, que tienen como ámbito de desarrollo un producto turístico específico (turismo cultural, turismo de congresos...), un perfil de turistas específico (turismo de tercera edad, turismo joven, turismo social...) o una temática concreta del turismo (sostenibilidad, concentración, seguridad...) (Velasco 2004).

\section{a) Programas de impulso a productos turísticos}

Una de las líneas de acción con mayor presencia en las declaraciones programáticas de los diferentes Gobiernos en materia de política turística es la diversificación de la oferta turística mediante el impulso de productos turísticos alternativos al tradicional y consolidado de sol y playa. Esta idea también se refleja en el trabajo de los Grupos parlamentarios.

Sirvan como ejemplo los objetos de las siguientes iniciativas parlamentarias: Programas para fomentar el turismo deportivo, medidas para potenciar el ecoturismo en la cornisa cantábrica, importancia dada a la gastronomía para incluirla en la agenda cultural desde el punto de vista turístico...

En la VI Legislatura el Grupo Socialista presenta dos proposiciones no de ley: una, ante el Pleno, para combatir la estacionalidad y mejorar el empleo en el sector turístico de sol y playa, que es aprobada, y otra en Comisión, para instar al Gobierno a realizar una promoción específica del turismo termal. 
En la VII Legislatura, el Grupo Popular, en el Gobierno, presenta una proposición no de ley ante el Pleno, que acaba calificándose para llevarse a Comisión con el objeto de diseñar medidas para estimular la creación de oferta turística y la comercialización de recursos especialmente culturales.

\section{b) Programas para facilitar la realización de turismo de colectivos determinados}

De entre los diferentes colectivos que pueden ser objeto de programas concretos (jóvenes, discapacitados, etc.) el programa de turismo social para la tercera edad es, con mucha diferencia, el programa que concentra el mayor número de iniciativas del Congreso de los Diputados.

El programa dio comienzo en 1985 impulsado por el INSERSO y se mantiene desde entonces. Nunca ha sido un programa gestionado por las organizaciones de política turística aunque siempre ha tenido, entre sus objetivos, la desestacionalización de destinos turísticos de sol y playa, razón por la que se le cambia el nombre por Programa de Vacaciones para mayores y para mantenimiento del empleo en zonas turísticas.

Durante la Legislatura que se impulsó, la III, se presentaron por el Grupo Popular ciento veinte preguntas al Gobierno con respuesta escrita sobre distintos aspectos del citado Programa (básicamente relativas al número de beneficiarios por provincias, por trimestre, al número de puestos de trabajo que se crearían, a los resultados obtenidos, etc.), lo que evidencia el recelo político que supuso, desde una perspectiva partidista, por la presunción de su rentabilización política.

En la VI Legislatura, durante la cual el programa sufre diversas modificaciones, vuelve a ser objeto del interés de los Grupos que preguntan sobre él en veinticuatro ocasiones.

\section{c) Programas centrados en asuntos concretos que afectan a la totalidad del sector}

En este epígrafe se agrupa la actividad parlamentaria cuyo objeto son diferentes asuntos sobre los que trabaja el Gobierno central y que resultan de importancia para el conjunto del desarrollo turístico.

El grupo más importante de iniciativas, también en términos numéricos, es el relativo a programas de promoción. En 84 ocasiones se pone en marcha algún tipo de iniciativa relacionada con la que resulta ser una de las competencias de mayor importancia de la Administración General del Estado en materia de turismo.

Todas ellas, salvo en una ocasión, son iniciativas de control. En la VI Legislatura, el Grupo Popular -en el Gobierno- como reacción a varias preguntas del Grupo Socialista sobre el asunto, presenta una proposición no de ley en Comisión para declarar del interés turístico nacional «el paso» de Semana Santa de Alhaurín el Grande (provincia de Málaga). Iniciativa que no tiene ninguna relevancia para la política de promoción del turismo.

En un segundo grupo se encuadran las iniciativas parlamentarias relacionadas con los temas de calidad que son objeto de atención de los Grupos parlamentarios del Congreso en 27 ocasiones

La relación del turismo con el medio ambiente, incluyendo los asuntos relacionados con la idea de sostenibilidad turística sólo aparece como objeto de trabajo en el Congreso durante la VI y VII Legislatura (de 29 iniciativas que se centran en este objeto en todo el periodo estudiado, 25 de ellas corresponden a estas dos Legisla- 
turas). Y de todas las iniciativas presentadas sólo en una ocasión se utiliza un instrumento de orientación política: en la VI se presenta una proposición no de ley en Comisión, por el Grupo Federal Izquierda Unida, para que el Gobierno reconsidere las autorizaciones dadas para la construcción de un funicular en el Parque Nacional de los Picos de Europa, en Asturias. La propuesta es rechazada.

Por último, la formación turística es objeto de 47 iniciativas, como por ejemplo: grado de conformidad del Ministerio respecto del sistema de estudios y titulaciones relativas al turismo, planes para integrar la carrera de turismo en la Universidad, plan de formación y reciclaje de trabajadores y directivos del sector, utilización de fondos para formación profesional en el sector turístico, etc.

Igualmente significativo es que algunos asuntos no hayan sido objeto de trabajo por parte de los Grupos parlamentarios. Hemos observado el número de iniciativas que tuvieran por objeto algunas de las siguientes cuestiones (todas de gran importancia en el discurso de la política turística):

- La posibilidad de generar un estatuto peculiar para el municipio turístico. Los problemas de desequilibrio entre el aumento de servicios que los municipios turísticos soportan en temporada alta y los recursos financieros que tienen para hacerles frente son la causa de que, desde hace varias décadas, se hable de la necesidad de aprobar un estatuto específico para este tipo de municipio. Este asunto, de importancia evidente, sólo se trata en las dos últimas Legislaturas. Es objeto de 20 iniciativas (aunque 8 de las cuales son la remisión al Congreso del acuerdo que se toma en sendos Ayuntamientos para la elaborar, por ellos mismos, un estatuto de municipio turístico). Tan sólo en una ocasión se plantea una proposición no de ley en Comisión, durante la VII Legislatura, para la elaboración de un estatuto del municipio turístico que, a pesar de ser aprobada, no tiene ningún impacto.

- La protección consumidor turista es objeto de 4 iniciativas. Dos de ellas pretenden la acción política: en la IV el grupo CDS presenta una proposición no de ley en Comisión para la constitución del Centro Nacional de Defensa del Turista -que se aprueba pero no se constituye-; y durante la VI el Grupo Mixto insta, utilizando el mismo tipo de iniciativa, al Gobierno a que tome medidas para desarrollar una normativa reguladora de deportes y actividades de riesgo, que caduca.

- La protección del patrimonio cultural en relación con el turismo aparece sólo en 9 ocasiones, tres de ellas hacían referencia a la construcción de un hotel junto al acueducto de Segovia.

Otros asuntos, que deberían conformar el debate político, tienen una frecuencia tan baja que no parece coherente destacarlos, aunque los datos pueden verse en la Tabla 2. 


\section{GRÁFICO 5}

Iniciativas cuyo objeto son programas concretos

\section{PROGRAMAS}

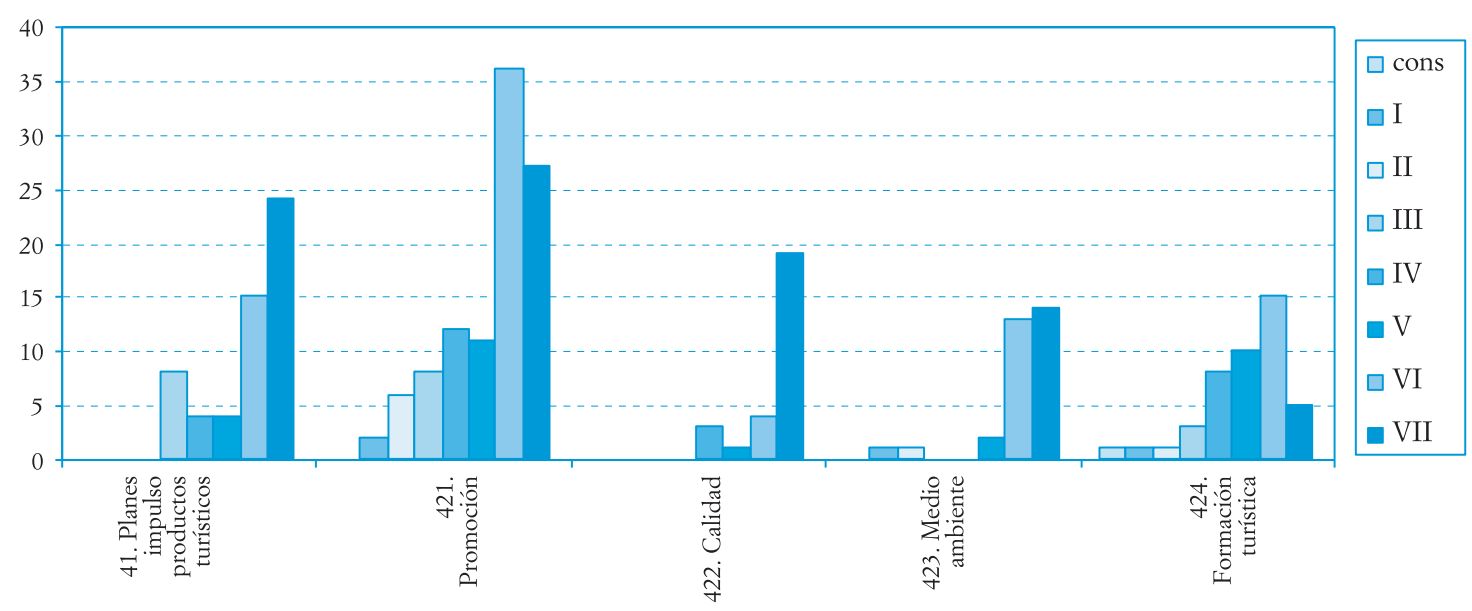

Fuente: Elaboración propia.

TABLA 2

Iniciativas parlamentarias cuyo objeto son programas concretos

\begin{tabular}{|c|c|c|c|c|c|c|c|c|c|}
\hline Programas & Const. & I & II & III & IV & $\mathrm{V}$ & VI & VII & TOTAL \\
\hline Planes impulso productos turísticos & & & & 8 & 4 & 4 & 15 & 24 & 55 \\
\hline Turismo social & & & 2 & 120 & 6 & 3 & 28 & 3 & 162 \\
\hline \multicolumn{10}{|l|}{ Programa: tema concreto } \\
\hline Promoción & & 2 & 6 & 8 & 12 & 11 & 36 & 27 & 102 \\
\hline Calidad & & & & & 3 & 1 & 4 & 19 & 27 \\
\hline Medio ambiente & & 1 & 1 & & & 2 & 13 & 14 & 31 \\
\hline Formación turística & 1 & 1 & 1 & 3 & 8 & 10 & 15 & 5 & 44 \\
\hline Municipio turístico & & & 1 & & & & 9 & 10 & 20 \\
\hline Protección del consumidor turista & & & & & 1 & & 1 & 1 & 3 \\
\hline Protección del patrimonio histórico & & & 1 & & & & 3 & 5 & 9 \\
\hline Accesibilidad & & & & & & & 4 & 2 & 6 \\
\hline Euro & & & & & & 1 & 5 & & 6 \\
\hline Nuevas tecnologías & & & & & & & 1 & 2 & 3 \\
\hline Señalización & & & & & & & 3 & 1 & 4 \\
\hline
\end{tabular}

Fuente: Elaboración propia. 


\subsection{Los datos sobre la actividad turística en España}

Uno de las características más relevantes de la política turística en España es la insistencia de los políticos en el valor -casi absoluto- de los datos y cifras que expresan la magnitud del fenómeno turístico. Ya hemos argumentado en otros trabajos que las cifras son meros indicadores cuantitativos, de alcance limitado, que no permiten conocer, por si mismos y en profundidad, cuáles son las características reales de un modelo turístico de un país como el nuestro que, desde 1952, presenta un crecimiento sostenido de llegadas de visitantes y un aumento, casi constante, del volumen de ingresos vinculado a la actividad turística.

Esta orientación a los datos también se refleja en la actividad del Congreso de los Diputados. Es significativo que existan 88 iniciativas parlamentarias cuyo objeto es que el Gobierno facilite diferentes información relativa a diferentes cifras turísticas (las más frecuentes se refieren a entrada de visitantes o turistas, gasto medio, ocupación, etc), frente a, por ejemplo, 64 que se interesan por los planes generales que elabora el Gobierno para el impulso del sector.

\subsection{Instrumentos financieros para apoyar la política turística}

Otro de los asuntos que se convierten en objeto de la actividad parlamentaria en materia de turismo son los recursos públicos que se dedican al sector. En este punto las iniciativas se centran en dos ámbitos: de una parte la actividad de propuesta y control de presupuesto y, de otra, los distintos instrumentos financieros de apoyo a la actividad o a los empresarios del sector, tales como inversiones públicas, líneas de crédito turístico o subvenciones.

Se observa cierta regularidad en los temas de presupuestos, inversión y crédito, asuntos que están presentes en la política turística durante todo el periodo estudiado. En cambio, las subvenciones aparecen en la IV Legislatura porque es entonces cuando, mediante el primer Plan Futures, se articulan dos líneas de subvenciones, una dirigida a la mejora de las empresas turísticas y otra a la oferta. Ambas se completarán con una línea de apoyo a la internacionalización de las empresas del sector.

TABLA 1

Temas objeto de las iniciativas según legislaturas

\begin{tabular}{|l|c|c|c|c|c|c|c|c|c|}
\hline \multicolumn{1}{|c|}{ Instrumentos financieros } & Const. & I & II & III & IV & V & VI & VII & TOTAL \\
\hline Control de presupuestos & & 4 & 1 & 16 & 27 & 19 & 32 & 13 & 112 \\
\hline Inversión pública & & & 6 & 6 & 8 & 12 & 49 & 23 & 104 \\
\hline Subvenciones & & & & 4 & 16 & 15 & 5 & 40 \\
\hline Crédito turístico & & & 8 & 2 & 5 & 2 & 2 & \\
\hline & & & 15 & 24 & 44 & 49 & 98 & 41 & 275 \\
\hline
\end{tabular}

Fuente: Elaboración propia. 


\subsection{Iniciativas sobre el sector empresarial turístico}

El turismo es un fenómeno social que se desarrolla a través de un sector empresarial que utiliza en la configuración de sus productos bienes y servicios públicos de diferente naturaleza (desde recursos territoriales, naturales, culturales, etc., hasta infraestructuras de transporte o servicios sanitarios).

Como la competencia en materia de ordenación y promoción del turismo es exclusiva de las Comunidades Autónomas no tendríamos porqué encontrar iniciativas que tengan al sector empresarial como objeto central. Pero, dada la importancia de la actividad (y protegidos por el argumento de la intervención estatal derivada de la competencia de coordinación de la economía general), encontramos alguna iniciativas que inciden sobre alguno de los subsectores o algunos de los asuntos básicos del tejido empresarial turístico.

\section{a) Subsectores turísticos}

Es muy significativo, y un claro reflejo del subsector dominante en materia de turismo, que en cuarenta y cuatro ocasiones un Grupo parlamentario se haya interesado por alguna circunstancia que afectaba al subsector de alojamiento: partes de entrada y libros de registro de viajeros en hostelería; ayudas y subvenciones concedidas a instalaciones turísticas y hoteleras en las provincias de Málaga, Barcelona, Las Palmas, Baleares, Valencia, Sevilla y Alicante, etc.

Dentro de este grupo, un conjunto significativo lo forman iniciativas cuyo objeto es la modernización de los alojamientos privados: medidas para la renovación y modernización de la planta hotelera obsoleta; impulsar un plan de remodelación de la planta hotelera de la Costa del Sol; previsiones en inversiones y localización para renovación, mejora y modernización de establecimientos turísticos de la provincia de Córdoba en 1997, etc.

Sólo en diez ocasiones el Congreso ha fijado su atención en la intermediación (y normalmente para señalar problemas relacionados con turoperadores). Aunque relacionado con este subsector se encuentra la única Ley que, en todo el periodo, se logro consensuar con todas las Comunidades Autónomas y aprobar para ser de aplicación a todo el territorio nacional y que se trata del Proyecto de Ley reguladora de los Viajes Combinados. Hay que advertir, no obstante, que en este sentido existía una directiva previa europea que era necesario incorporar en nuestro marco normativo. Pero, en todo caso, el trabajo de coordinación fue destacable.

\section{b) Mercado de trabajo turístico}

Otro grupo, aunque muy modesto, lo forman las iniciativas que versan sobre el mercado de trabajo turístico. Teniendo en cuenta lo que el sector representa en términos de empleo y la frecuente inclusión del asunto como un asunto a abordar por el Gobierno, es significativo que sólo haya sido objeto de 20 iniciativas durante 25 años de actividad parlamentaria. 


\section{GRÁFICO 6}

Iniciativas cuyo objeto son el sector empresarial

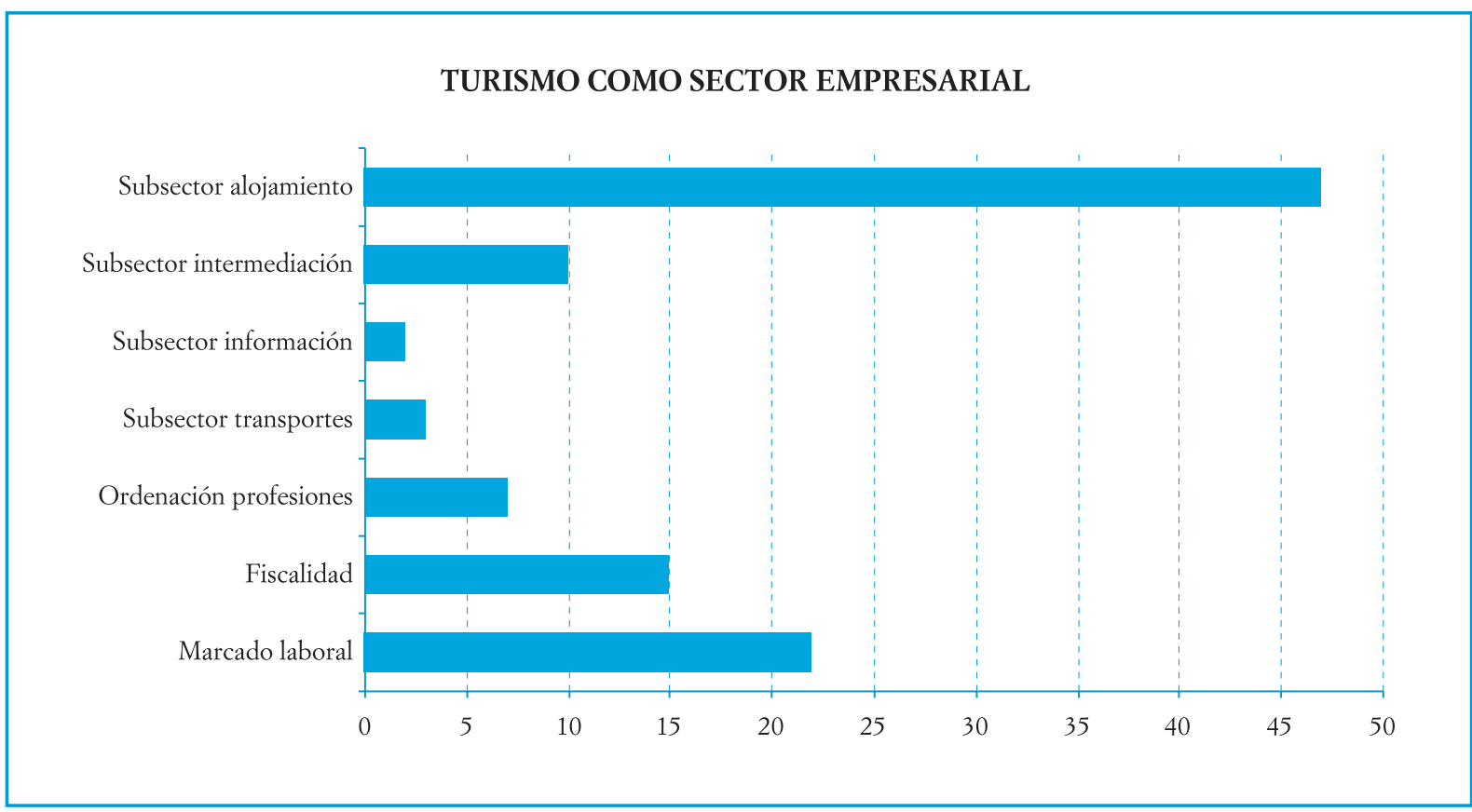

Fuente: Elaboración propia.

\subsection{Infraestructuras y servicios vinculados al turismo}

El turismo necesita para su desarrollo diferentes tipos de infraestructuras y servicios que permitan el desarrollo de la actividad. Su presencia no es demasiado significativa quizá porque son cuestiones que afectan a la totalidad del territorio, superando con mucho al sector.

Aunque existen algunas iniciativas que se centran en infraestructuras -20 en todo el periodo ( 7 en servicios), lo más significativo es el aumento, en la VII Legislatura de aquellas que tienen por objeto la seguridad -37, de las cuales 20 se plantean en la séptima legislatura-, reflejando la creciente preocupación social por este asunto en cualquiera de los ámbitos.

\subsection{Paradores de turismo}

Las iniciativas que tienen por objeto cuestiones relacionadas con la sociedad estatal Paradores de Turismo de España ocupan un lugar destacado. Los paradores son un elemento simbólico del desarrollo turístico español que quedó vinculado al Gobierno central ${ }^{13}$ y se han convertido en un asunto protagonista del debate parlamentario por diversas razones.

${ }^{13}$ Organismo autónomo creado en 1958, durante la dictadura franquista. Mantuvo la misma estructura y naturaleza jurídica hasta 1990, en que se transforma en una sociedad estatal denominada «Paradores de Turismo de España». 
En primer lugar porque, desde la transición política, los decisores públicos en materia de turismo anunciaron su intención de sanear la gestión de los establecimientos estatales, haciendo de ellos un instrumento de diversificación de la oferta. Ello planteaba dudas acerca de la conveniencia de su privatización e, incluso, sobre su posible traspaso a las Comunidades Autónomas. Y en segundo lugar porque, como consecuencia del prestigio de la cadena, los partidos y Grupos han llevado con frecuencia al Parlamento cuestiones diversas (ubicación de futuros paradores, modernización de las instalaciones de los existentes...) que les trasladaban municipios diversos.

En 152 ocasiones se plantean cuestiones relativas a la inversión en paradores concretos y en 83 se han formulado preguntas sobre aperturas o posibles cierres de establecimientos. La estrategia general del Gobierno en relación con la cadena de Paradores de Turismo aparecen sólo en 25 iniciativas, aunque hemos codificamos aparte 29 cuestiones relativas a su posible privatización. Y también en este caso constituyen abrumadora mayorías las iniciativas relacionadas con la función de control. Del total, sólo 7 podrían considerarse de orientación política.

Tres de ellas estaban relacionadas con la apretura de un nuevo establecimiento. En la Legislatura Constituyente se presenta por el Grupo Popular una proposición no de ley en la Comisión de Comercio y Turismo para que se abra un parador en el municipio de Pajares, en Asturias. En la VI, el Grupo Socialista propone a la Comisión de Industria, Energía y Turismo la construcción parador en Alcalá la Real (Jaén), propuesta que caducó. Y en la VII, obras en el monasterio de San Vicente en Monforte de Lemos para construir un parador.

Otra iniciativa de este conjunto proponía una línea de acción concreta: durante la I Legislatura el Grupo Socialista plantea en la Comisión de Cultura una proposición no de ley para controlar el precio de los paradores durante el Campeonato Mundial de Fútbol de 1982, proposición que fue rechazada por la Comisión.

Una quinta pretendía obtener información sobre la política general del organismo. Durante la V Legislatura, el Grupo Federal Izquierda Unida-Iniciativa per Catalunya presenta una proposición no de ley en Comisión en la que insta al Gobierno a remitir al Congreso una comunicación sobre Plan Estratégico de Paradores Nacionales. La iniciativa es rechazada.

Y, finalmente, en dos iniciativas se pide al Gobierno la cesión o transferencia de algún parador: en la III Legislatura el Grupo Coalición Popular presenta una proposición no de ley en la Comisión de Industria, Obras Públicas y Servicios para que el Gobierno central ceda el Parador de Portomarín (Lugo) al Ayuntamiento o Diputación, propuesta que es rechazada y, durante la V Legislatura, el Grupo Federal Izquierda Unida-Iniciativa per Catalunya, pide al Gobierno cumpla las Previsiones del artículo 9.12 del Estatuto de Autonomía de Cataluña y se transfiera la titularidad y gestión de los paradores de turismo y la gestión de acción concertada para la promoción del turismo.

\section{Conclusiones}

Los Grupos parlamentarios han realizado un trabajo intenso en relación con la política turística durante las siete Legislaturas. El número y variedad de los asuntos tratados evidencia que el Parlamento ha considerado relevante la política turística independientemente de que éste no tiene un papel protagonista ya que, al carecer el Gobierno central de competencia sobre este asunto, ninguna de las iniciativas parlamentarias del periodo corresponde a la función legislativa.

A pesar de ello, el Parlamento se centra casi exclusivamente en la función de control interesándose por actuaciones ya realizadas, por problemas coyunturales o por situaciones que irrumpen en la agenda política. Esto 
describe un estilo claramente reactivo de un Parlamento y, sobre todos, de unos Grupos parlamentarios que ni en ocasiones favorables, como en situación de Gobierno en minoría, se plantean una acción decidida para introducir cambios en la política turística que reflejen otras opciones ideológicas.

En cambio, cuando la institución ha actuado como espacio de análisis, deliberativo y consensual, el resultado ha sido muy fructífero. Es destacable, por su impacto, que, como consecuencia de dos proposiciones no de ley ante el pleno, se instara al gobierno a celebrar un debate sobre la situación del sector en España y, tras ello, a crear una ponencia parlamentaria para el análisis del sector turístico. Los trabajos de la Ponencia dan lugar a un informe que contiene las ideas claves en la política turística inmediatamente posterior, concertadas en el Plan Futures de 1991. Este plan supone, desde el análisis de la política turística, el primer conjunto articulado de acciones que lidera el Gobierno Central y resultan de interés para las Comunidades Autónomas, dando sentido a su papel en el conjunto de la política turística.

En relación con el trabajo que los Grupos parlamentarios han podido realizar teniendo por objeto los diferentes instrumentos organizativos creados o modificados por el Gobierno para intervenir en materia de turismo lo más sorprendente es que el funcionamiento de los instrumentos de cooperación -entre Gobierno Central y Comunidades Autónomas y entre aquéllos y el sector privado- no genera ningún interés desatacado.

En relación con los planes, sólo son objeto de trabajo recurrente los planes centrados en destinos. Esto refleja compromisos de los parlamentarios con sus circunscripciones, sin que sea posible encontrar un discurso crítico global ni una posición de un grupo que plantee alguna alternativa a los instrumentos diseñados.

Debemos también destacar como un dato significativo que, durante las siete legislaturas, no existen temas que formen parte de una línea de acción coherente de ningún partido político. Todos trabajan de manera homogénea sobre los mismos asuntos. Esta característica, sorprendente, empieza a quebrarse en la VI y VII Legislatura en donde el Grupo Socialista incorpora entre los asuntos que trabaja algunas cuestiones relativas a la relación entre turismo y medio ambiente o turismo y accesibilidad para personas con discapacidad, pero de manera débil.

Tanto que, el mercado laboral del primer sector en términos de empleo del país, la protección del consumidor turista, los problemas de formación de los trabajadores del sector o la relación del turismo con el patrimonio cultural, no han estado en la agenda de ningún Grupo parlamentario, aunque sí en varios programas electorales.

En cambio hay 88 iniciativas, cuya autoría corresponde a diversos Grupos parlamentarios, que se interesan por el número de turistas que llegaron o por los ingresos que estos dejaron. El Parlamento refleja la unidimensionalidad que sufre la propia política turística: una política que nunca se ha permitido el cuestionamiento del modelo por la bondad de las cifras que lo caracterizan.

Todos los datos parecen indicar que existe, independientemente de cuál sea el partido en el gobierno y quién asuma la oposición parlamentaria, un acuerdo básico sobre los aspectos de la actividad que no se cuestionan. El debate se centra en los medios para mejorar la oferta existente o en corregir algunas disfuncionalidades que afectan al propio desarrollo del sector, pero no se cuestiona por ningún Grupo la naturaleza de una política turística que apuesta por un modelo de desarrollo turístico cuyo objetivo es el mantenimiento de los ingresos a través de un altísimo número de turistas, con un gasto medio muy bajo, que aún anteponen un precio económico a un entorno medioambientalmente sostenible, que se concentran en zonas saturadas, dedicadas, mayoritariamente, al soy y playa.

El Parlamento, en un sistema político como el nuestro, tiene un papel en el proceso de elaboración de políticas públicas que parece limitarse a la función de control a posteriori de las acciones impulsadas por el Ejecu- 
tivo, sin que la institución haya desplegado la función de impulso o se haya personado en los procesos de definición de los problemas a través del trabajo parlamentario.

Pero, en nuestra opinión, esto no es consecuencia tanto de las restricciones sistémicas y reglamentarias cuanto de la dinámica de trabajo interna que parece no facilitar ni el mantenimiento de parlamentarios especializados en políticas concretas ni un trabajo prospectivo que precisara la elaboración de propuestas. Los Grupos no elaboran estrategias, no defienden discursos homogéneos y sus discursos, al menos en la política turística, no se diferencian sustancialmente.

Aún así, como el objeto del presente trabajo es una sola arena, es posible plantearse que los Grupos no se comporten igual cuando trabajan en otras arenas e inviertan sus recursos en otras políticas con opciones ideológicas más claras o componentes simbólicos con mayor impacto externo.

El turismo es un tema que, sin duda, ha interesado e interesa en el Parlamento. A pesar de ello, la institución no ha tenido un peso destacable en la construcción de la política turística, quizá si observamos otra política concreta podamos extraer conclusiones opuestas. Ese será el objeto de un nuevo trabajo.

\section{REFERENCIAS BIBLIOGRÁFICAS Y DOCUMENTALES}

Aguiló Pérez E. y Vich i Martorell E. M. (1996), «La investigación en el ámbito de la política turística», Estudios Turísticos 129: 23-35.

Antón i Clavé, S. et al. (1996), «La investigación turística en España: aportaciones de la Geografía (1960-1995)», Estudios Turísticos 129: 165-208.

Banco Interamericano de Desarrollo (2006), La política de las políticas públicas. BID: Departamento de Investigación. http://www.iadb.org/res/ipes/2006/index.cfm?language=Sp

Blanquer Criado, D. (2002), Ordenación y gestión del territorio turístico. Valencia: Tirant Lo Blach.

Börtzel, T. (1998), «Organizing Babylon: on the Different Conceptions of Policy Networks», Public Administration Review (76) 2: 253-273.

Bote Gómez, V. (1993), «La necesaria revalorización de la actividad turística española en una economía terciarizada e integrada en la CEE», Estudios Turísticos 118: 2-26.

- (1996a), «Política Turística», en V. M. Monfort, et al. Introducción a la Economía del Turismo en España. Madrid: Cívitas: 295-326.

- (1996b), «La investigación en España sobre Turismo y desarrollo económico», Estudios Turísticos 129: 9-22.

Caballero, G. (2005), «La organización industrial del Congreso de los Diputados: la Gobernanza de los procesos parlamentarios». X Congreso de Ciencia Política y de la Administración: Madrid.

Caballero, G. y Arias X. C. (2003), «Una reorientación teórica de la economía política: el análisis político de costes de transacción», Revista Española de Ciencia Política 8: 131-164.

Cals, J. (1987), «Turismo y política turística en España 1974-1986», en J. Velarde et al., eds., El sector terciario de la economía española. Madrid: Economistas Libros.

Caretti, P. y Morisi, M. (2001), «Parlamento e polotiche pubbliche», Quaderni Costituzionali (XXI) 3: 491-504. 
Considine, M. (2005), Making public policy. Cambridge: Polity Press.

Cox, G. W. y McCubbins, M. D. (2001), «The Institutional Determinants of Economic Policy Outcomes», en S Haggard y M. D. McCubbins, eds., Presidents, Parliaments, and Policy. Nueva York: Cambridge University Press.

Döring, H. y Hallerberg, M. (2004), Patterns of parlamentary behaviour: passage of legislation across Europe. Aldershot: Asgathe.

Edgell, D. L. (1999), Tourism policy: the next millenium. Champaig: Sagamore.

Fenger, M. y Klok, P. (2001), «Interdependency, beliefs and coalition behavior: A contribution to the advocacy coalition framework», Policy Sciencies 34: 157-170.

Ferejohn, J. et al. (2001), Constitutional culture and democratic rule. Cambridge: Cambridge University Press.

Figuerola Palomo, M. (1985), Teoría económica del turismo. Madrid: Alianza Editorial.

- (1993), «Política de Turismo», en L. Gámir, coord., Política económica de España. Madrid: Alianza.

Fischer, F. y Forester, J. (1993), The Argumentative Turn in Policy Analysis and Planning. Londres: Duke University Press y UCL Press.

García Reche, A. y Nácher Escriche, J. (1999), «Política Turística», en A. G. Reche, coord., Política económica sectorial y estructural. Valencia: Tirant Lo Blanch.

Hall, C. M. (2000), Tourism planning. Policies, processes and relationships. Essex: Prentice.

Hall, C. M. y Jenkins, J. M. (1995), Tourism and Public Policy. Londres: Routledge.

Hill, M. (1997), The Policy Process in the Modern State. Nueva York: Prentice-Hall.

Instituto de Turismo de España (2005), Balance del turismo en España. www.iet.tourspain.es.

Instituto Nacional de Estadística (2006), Cuenta satélite del turismo en España. www.ine.es.

Ivars, J. (2003), Planificación turística de los espacios regionales en España. Madrid: Síntesis.

Johnson, P. y Thomas, B. eds., (1992), Perspectives on tourism policy. Londres: Mansel.

Keller, P. (1999), «Futured-oriented tourism policy: Strategic areas of inquiry». Portoroz: 49th Congress AIEST.

Lanzaro, J. ed., (2001), Tipos de presidencialismo y coaliciones políticas en América latina. Buenos Aires: Consejo Latinoamericano de Ciencias Sociales (CLACSO).

Lindblom, C. E. y Woodhouse, E. J. (1993), The Policy-Making Process. Englewood Cliffs: Prentice-Hall.

Loewenberg, G. y Squire, P. eds., (2002), Legislatures. Ann Arbor: The University of Michigan Press.

López Nieto, L. ed., (2004), Relaciones entre Gobiernos y Parlamentos Autonómicos. Madrid: Departamento de Publicaciones del Senado.

Lukes, S. (1974), Power: A Radical View. Londres: McMillan.

Marchena Gómez, M. (1989), «El turismo en España: razones de Estado, política regional y ordenación del territorio», Boletín Económico del ICE 2197: 3399-3405.

Mény, Y. y Thoenig, J. C. (1991), «Políticas públicas y teoría del Estado», Documentación Administrativa 224-225.

Mezey, M. (1993), «Legislatures: Individual Purpose and Institutional Performance», en A. W. Finifter, ed., Political Science: the State of the Discipline. Washington: American Political Science. 
Monfort Mir, V. M. (2000), «La política turística: una aproximación», Cuadernos de Turismo 6: 7-27.

Morgenstern, S. (2002), «Towards a Model of Latin American Legislatures», en S. Morgenstern y B. Nacif, eds., Legislative Politics in Latin America. Cambridge: Cambridge University Press.

Nácher Escriche, J. (1999), «Competitividad y política turística», Boletin Económico del ICE 2610:25-34.

Norton, P. (1990), «Parliaments. A framework for analysis», Western European Politics 3: 1-9.

- (1993), Does Parliament matter? Londres: Harvester Wheatsheaf.

Packenham, R. A. (1990), «Legislatures and political development», en P. Norton, ed., Legislatures. Oxford: Oxford University Press.

Paniagua Soto, J. L. y Monedero, J. C. eds., (1999), En torno a la democracia en España. Temas abiertos del sistema político español. Madrid: Tecnos.

Paniagua Soto, J. L. y Velasco González, M. (2006), «El rendimiento del Parlamento en relación con una política pública: el caso de la política turística y el Congreso de los Diputados (1978-2004)», Revista de las Cortes Generales 68.

Patterson, S. y Copeland, G. (1994), Parliaments in the Modern World. Michigan: University of Michigan Press.

Pearce, D. G. (1996), «Regional tourist organizations in Spain: emergence, policies and consequences», Tourism Economics 2 (2): 119-136.

Pellejero Martínez, C. ed., (1999), Historia de la economía del turismo en España. Madrid: Biblioteca Cívitas de Economía y Empresa.

Portero Molina, J. A. (1998), El control parlamentario del Gobierno. ICPS Working Papers. Barcelona.

Putman, R. (1993), Making Democracy work. Berkeley: Berkeley University Press.

Reboredo, R. (1998), «Más allá del control parlamentario, el impulso político», en F. Pau, coord., Parlamento y control del Gobierno. Pamplona, V Jornadas de la Asociación Española de Letrados de Parlamento: Aranzadi.

Sabatier, P. A. (1999), Theories of the policy process. Boulder: Westview.

Sabatier, P. A. y Jenkins-Smith, H. eds., (1993), Policy Change and Learning. An Advocacy Coalition Approach. Boulder: Westview Press.

Saiegh, S. (2005), The Role of Legislatures in the Policymaking Process. Trabajo preparado para el Workshop on State Reform, Public Policies and Policymaking Processes del BID. Washington, DC (28 de febrero-2 de marzo).

Subirats, J. (1994), Análisis de políticas públicas y eficacia de la administración. Madrid: MAP.

Subirats, J. y Gallego, R. eds., (2002), Veinte años de autonomías en España. Leyes, políticas públicas, instituciones y opinión pública. Madrid: CIS.

Troitiño Vinuesa, M. A. (1996), Turismo y desarrollo sostenible en ciudades históricas. Madrid: Instituto de Turismo de España.

Tsebelis, G. (1999), «Veto Players and Law Production in Parliamentary Democracies: An Empirical Analysis», American Political Science Review 93 (3).

USAID (2000), Handbook on Legislative Strengthening. Technical Publication Series: bttp://www.usaid.gov/our_work/democracy_and_governance/publications.

Valdés Peláez, L. (2002), «La política turística de la Unión Europea: nuevas orientaciones». IV Congreso Andaluz de Turismo. 
Velasco González, M. (2004), La política turística. Gobierno y Administración Turística en España (1952-2003). Valencia: Tirant Lo Blanch.

- (2005a), «Administración y política turística de 1978 a 2005», Estudios Turísticos 163-164: 99-123.

- (2005b), «¿Existe la política turística? La acción pública en materia de turismo en España (1951-2004)», Política y Sociedad 42.

Vera Rebollo, J. F. et al. (1999), Análisis territorial del turismo. Barcelona: Ariel.

Vera Rebollo, J. F. y Marchena Gómez, M. (1990), «Turismo y desarrollo: un planteamiento actual», Papers de Turismo 3: 59-84.

Warden, F. V. (1992), «Dimensions and types of policy networks», European Journal of Political Research 21.

Weaver, R. K. y Rockmann, B. R. eds., (1993), Do Institutions Matter? Government Capabilities in the Unites States and Abroad. Washington: Brookings Institution.

Weingast, B. R. y Marshall W. J. (1988), «The Industrial Organization of Congress; or, Why Legislatures, Like Firms, Are Not Organized as Markets», Journal of Political Economy 96: 132-163.

Yanes, A. (1998), «Mociones, interpelaciones y preguntas», en F. Pau, coord., Parlamento y control del Gobierno. Pamplona, V Jornadas de la Asociación Española de Letrados de Parlamento: Aranzadi. 


\section{Experiencias y Casos}

